\title{
A quantitative study into the role of infection in determining nutritional status in Gambian village children
}

\author{
By M. G. M. ROWLAND, T. J. COLE AND R. G. WHITEHEAD \\ Dunn Nutritional Laboratory, University of Cambridge and \\ Medical Research Council, Milton Road, Cambridge CB 4 IXF, and \\ Medical Research Council Laboratories, Keneba, The Gambia
}

(Received 19 Fuly 1976-Accepted 6 September 1976)

\begin{abstract}
1. Growth in weight and height in 152 children between the ages of 0.6 and 3 years was investigated in Keneba, a rural Gambian village. By I year of age the average weight-for-age of the children was only $75 \%$ of the Jelliffe (1966) standard.

2. The relationship between the prevalence of nine different categories of diseases and growth was investigated to determine the quantitative contribution of the diseases to the growth faltering observed. There was a highly significant negative relationship between gastroenteritis and both weight gain and height gain. The only other disease category having a similar relationship was malaria, but in this instance only with weight gain.

3. Although over-all growth in weight and height was considerably below the standard values, multiple regression analysis indicated that after the age of I year, except in July and August, normal and sometimes slow 'catch-up' growth would be possible in the absence of gastroenteritis.

4. Attention is drawn to the limitations of the use of anthropometry in a settled village community as the only criterion by which dietary adequacy can be judged.
\end{abstract}

It is now well established that the 'nutritional' status of a child is usually as much the product of infection as of diet (for review see Scrimshaw, Taylor \& Gordon, 1968; Scrimshaw, 1975). International criteria for assessing nutritional status are largely based on the interpretation of weight and height measurements, but results of longitudinal studies in various parts of the world have convincingly shown that periods of growth faltering reflect the pattern of infection at least as much as changes in dietary pattern (Mata, Urrutia \& Gordon, 1967; McGregor, Rahman, Thomson, Billewicz \& Thompson, I970; Frood, Whitehead \& Coward, 1971; Martorell, Habicht, Yarbrough, Lechtig, Klein \& Western, I975). This means that any effective intervention programme directed at improving the nutritional status of a community must take into account local disease patterns as well as dietary inadequacies.

Studies into the effects of infection (Morley, 1962; McGregor et al. 1970; Frood et al. 197I; Poskitt, 1972) have established a qualitative association between individual diseases such as malaria, measles and gastroenteritis and the appearance of clinical signs of protein-energy malnutrition. There have been few quantitative studies, however, though an attempt at establishing a more precise relationship was made by Mata, Jimenez, Cordon, Rosales, Prera, Schneider \& Viteri (1972) and extended by Martorell et al. (1975). Only with an understanding of the quantitative effect of different infections on growth or other nutritional indices, can one proceed 
442 M. G. M. Rowland, T. J. Cole and R. G. Whitehead 1977

to establish priorities when recommending specific preventive health measures directed towards improvement of the nutritional status of a community.

This report, which is based on work carried out on individual children in Keneba and neighbouring villages in The Gambia, West Africa, attempts to quantify the contribution of different infections to the pattern of growth during the first 3 years of life. The role of diet will be described elsewhere.

\section{METHODS}

\section{Subjects}

The three villages studied, Keneba, Kantonkunda and Manduar, are situated in the centre of a small rural peninsular bounded by the Bintang bolon and the River Gambia. They are about 80 miles from the capital, Banjul, and their relative isolation is partly because they lie off the main road system. There is a permanent Medical Research Council field station in Keneba, run by a qualified British paediatrician (M.G.M.R.).

In April 1974, after gaining parents' permission, children from the three villages were introduced into the study. Children born subsequently were also invited to join at 3 months of age. Collection of information ceased when the children were 3 years old; the study was completed by November 1975 , having spanned one dry and two rainy seasons. The number and percentage of total possible children collaborating throughout this period in Keneba, Kantonkunda and Manduar was $152(92 \%), 44(77 \%)$, and $18(50 \%)$ respectively. Since the 'drop-out' rate in Manduar was so high, recruitment from this village was halted at an early stage, and, as the results from Kantonkunda closely reflected those from Keneba, only the results from Keneba are reported here.

\section{Collection of information}

Survey children were brought to the clinic routinely at intervals of $I$ month and at other times when the mothers sought medical help. At the routine clinic visits measurements of height and weight were made and a clinical history and full examination were carried out.

Stool and urine microscopy, and for a limited period stool bacteriology, were also performed. Blood was taken and thick films were examined for evidence of malaria; routine haematological measurements were carried out using a Coulter Counter (Model ZF; Coulter Electronics Ltd, Dunstable, Beds, UK).

Medical attention was freely available at all times to the subjects in the event of intercurrent illnesses. Parents were encouraged to make use of this service however trivial the complaint; regular transport was provided for this purpose. Thus assessments could be made of each clinical diagnosis and of the duration of each individual illness. The clinical examinations were carried out by a single observer (M.G.M.R.). When possible, laboratory confirmation was sought to support the clinical diagnosis. 


\section{Disease categories}

Although there were more than eighty different diagnoses made during the period of investigation, illnesses were subsequently placed in nine categories to facilitate analysis. These categories were: (I) upper respiratory tract infections (URTI) which consisted of ear, nose and throat infections such as otitis media, coryza and pharyngitis; (2) lower respiratory tract infections (LRTI) which included bronchitis and pneumonia; the Court (1963) classification of respiratory disease was used; (3) gastroenteritis which was diagnosed on a history of diarrhoea with or without vomiting. Bloody diarrhoea (dysentery) was included in this group. Helminthic infections were extremely rare in the age-group studied; (4) infectious fevers which included measles, chicken pox, whooping cough and tuberculosis. During the period of study the only one to occur with any frequency was whooping cough, which was diagnosed in cases with cough, vomiting and possibly a 'whoop', continuing for more than I month and accompanied by an absolute lymphocytosis. The virtual absence of measles was due to a vaccination programme which was carried out in the course of the survey; (5) malaria which was defined as an acute febrile illness often accompanied by an acute enlargement of liver or spleen or both, plus a parasitaemia in excess of twenty organisms in each high-power microscopy field of a standard thick blood film, when the pyrexia could not be explained by any other intercurrent illness; (6) giardiasis which was diagnosed in the presence of free forms (trophozoites) identified by microscopy of fresh stool smears. This examination was carried out at each routine visit whether or not diarrhoea was present and also in cases of prolonged intractable diarrhoea; (7) superficial infections which included skin and eye infections plus minor trauma such as burns; (8) deep infections including cellulitis, abscesses and other deeper infections warranting antibiotic therapy; (9) nonspecific disorders, comprising all disorders not fitting into the other eight groups; these included abnormalities such as pyrexia of unknown origin, constipation and other miscellaneous disorders for which a definitive diagnosis could not be made.

In this paper no attempt has been made to grade the clinical severity of the different infections, although the length of time for which the child was affected is an essential feature of the statistical procedures.

\section{Anthropometry}

During the longitudinal study a series of anthropometric measurements were made, but only the results for weight and height are analysed here. Weight was measured using 'baby-weighing' scales (Todd's Scale Works, Cambridge, UK) and supine length was measured using a Harpenden stadiometer (Holtain Ltd, Dyfed, $\mathrm{UK})$.

\section{RESULTS}

The over-all impairment of growth which was found over the first 3 years of life during the study period is illustrated in Fig. I which shows the extent to which weight- and height-for-age had deviated from the internationally accepted standard (Jelliffe, 1966). Weight faltering was particularly dramatic during the first year of 


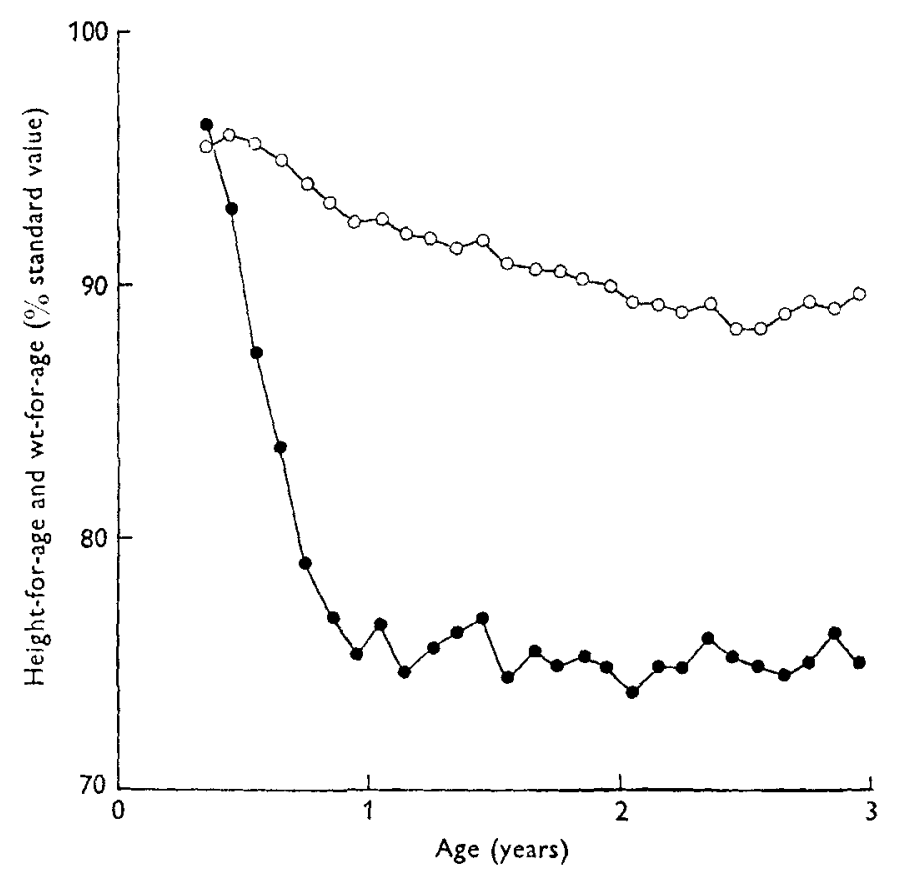

Fig. I. Mean values for height-for-age $(\mathrm{O}-\mathrm{O})$ and weight-for-age (-) for $\mathrm{I}_{2}$ Gambian village children between 0.3 and 3 years of age examined on a total of 1422 occasions at routine clinic visits during a study of nutritional status. Values are expressed as a percentage of the Jelliffe (1966) standard.

life, while that for height deteriorated progressively for 2 years and then, like weight, showed little sign of improvement. These findings were consistent with the results from a survey carried out by McGregor, Rahman, Thompson, Billewicz \& Thomson ( 1968 ) in the same area in $1962-3$.

\section{Relationship between different infections and growth}

The routine clinic measurements of height and weight were converted to gains in height and weight between adjacent clinic visits. The interval between visits was usually 4 weeks, but varied from 3 to ro weeks. Accordingly the height and weight gains were standardized to an interval of I calendar month, by dividing by the number of days in the interval and multiplying by $365 \div 12$.

The incidence of bouts of illness during the same interval was then determined. Taking each of the nine disease categories separately, the duration of the illness (d) in the interval between adjacent clinic visits was divided by the total duration of the interval (d) to give the relative period of illness (\%) for that interval. For convenience this value is referred to as the disease prevalence. For each interval values were obtained for height gain, weight gain and disease prevalence in each of the nine disease categories. Values for children aged less than 0.6 years were omitted, to avoid the neonatal factors i.e. a high growth rate and protection against infection provided by maternal antibodies. 
Table I. Regression coefficients with their standard errors calculated from the regressions of height gain and weight gain on nine categories of disease $t^{\text {in children aged } 0.6-3 \text { years }}$ from Keneba village, The Gambia

$\quad$ Category of disease
Upper respiratory tract infections
Lower respiratory tract infections
Gastroenteritis
Infectious fevers
Malaria
Giardiasis
Superficial infections
Deep infections
Non-specific disorders

\begin{tabular}{|c|c|c|c|}
\hline \multicolumn{4}{|c|}{ Regression coefficients } \\
\hline \multicolumn{2}{|c|}{ Height gain (mm/month) $\ddagger$} & \multicolumn{2}{|c|}{ Wt gain (g/month) $f$} \\
\hline Mean & SE & Mean & SE \\
\hline-0.8 & $\mathrm{t} \cdot 8$ & $-8 I$ & 79 \\
\hline$-3 \cdot 1$ & $2 \cdot 6$ & -53 & II 7 \\
\hline$-4 \cdot 2$ & $x \cdot 5 * *$ & -746 & $68 * * *$ \\
\hline$-1 \cdot 0$ & 3.0 & 79 & 135 \\
\hline-7.0 & $6 \cdot 0$ & -1072 & $268^{* * *}$ \\
\hline 0.3 & $2 \cdot 1$ & $-I 3 I$ & 93 \\
\hline$-0 \cdot I$ & $2 \cdot 0$ & 25 & 88 \\
\hline-0.9 & $2 \cdot 0$ & 27 & 91 \\
\hline$-I \cdot I$ & 4.9 & 440 & $219^{*}$ \\
\hline
\end{tabular}

* $P<0.05 ; * * P<0.01 ; * * * P<0.001$.

$\dagger$ For details, see p. 443 .

† Difference in growth rate between 100 and $\% \%$ prevalence for each category, where prevalence is calculated as: duration of illness (d) in the interval between routine visits $\div$ total duration (d) of interval between visits $\times 100$, where the interval varied from 3 to 10 weeks and was standardized to I calendar month.

A total of 12 Io values for the children from Keneba were included in the analysis, an average of about eight values/child. To determine whether there was any relationship between growth and disease, the values were subjected to multiple regression analysis, a procedure which simultaneously fits straight lines to the plots of growth (height gain and weight gain separately) $\boldsymbol{v}$. each of the nine categories of disease. The slope of each line is the regression coefficient, and it represents the change in growth rate during an episode of that illness, relative to that in children who do not have the disease.

The regression coefficients with their standard errors calculated from the regressions of height gain and weight gain $v$. disease prevalence are given in Table $\mathrm{I}$. For height gain, only gastroenteritis had a significant effect $(P<0.01)$. For weight gain, gastroenteritis was again prominent at a very high level of significance $(P<0.001)$ and malaria was also highly significant $(P<0.001)$. Paradoxically non-specific disorders had a positive effect $(P<0.05)$ but only for weight gain. This finding emphasizes the unsatisfactory nature of this grouping of miscellaneous diseases which was based largely on mothers' history and was often unsubstantiated by physical findings. Thus they may reflect a mother's natural tendency to over-diagnose illness in her child.

The analysis provides incontrovertible evidence that over-all the only disease categories which contributed significantly to weight faltering were gastroenteritis and malaria. Although larger values for regression coefficients were obtained for malaria compared with those for gastroenteritis for both height gain and weight gain, its standard errors were also larger, so that in terms of significance gastroenteritis was by far the more important. 
Table 2. Prevalence* of gastroenteritis and malaria and corresponding rates of growth between May 1974 and October 1975, during nine periods of 2 months for children aged 0.6 to 3 years $\dagger$ in Keneba village, The Gambia

(Mean values and standard deviations)

\begin{tabular}{|c|c|c|c|c|c|c|c|c|c|}
\hline \multirow[b]{2}{*}{ Period } & \multirow{2}{*}{$\begin{array}{l}\text { No. of } \\
\text { measure- } \\
\text { ments }\end{array}$} & \multicolumn{2}{|c|}{ Gastroenteritis } & \multicolumn{2}{|c|}{ Malaria } & \multicolumn{2}{|c|}{$\begin{array}{l}\text { Height gain } \\
(\mathrm{mm} / \mathrm{month})\end{array}$} & \multicolumn{2}{|c|}{$\begin{array}{c}\text { Wt gain } \\
\text { (g/month })\end{array}$} \\
\hline & & Mean & SD & Mean & sp & Mean & SD & Mean & SD \\
\hline I. May-June I 974 & 62 & 13.7 & 15.9 & 0.2 & I. 2 & 4 & IO & 13 & 461 \\
\hline 2. July-August 1974 & I 5 I & $17 \cdot 0$ & $21 \cdot 2$ & $I \cdot 3$ & $4 \cdot 5$ & 5 & 8 & -65 & 354 \\
\hline 3. September-October 1974 & 147 & $15 \%$ & $20 \cdot 0$ & $I \cdot 4$ & $3 \cdot 4$ & 5 & 8 & 143 & 438 \\
\hline 4. November-December 1974 & 149 & $8 \cdot 2$ & Ir 9 & $I \cdot 2$ & 4.4 & 8 & 8 & 297 & 373 \\
\hline 5. January-February 1975 & 95 & $12 \cdot 0$ & $18 \cdot 0$ & 0.0 & 0.1 & 9 & 7 & 225 & 341 \\
\hline 6. March-April r975 & I29 & $6 \cdot 9$ & $9 \cdot 3$ & 0.0 & 0.3 & 9 & 7 & 149 & $3^{8} 7$ \\
\hline 7. May-June 1975 & 100 & $I I \cdot I$ & $9 \cdot 8$ & 0.0 & 0.1 & 12 & 4 & 153 & 236 \\
\hline 8. July-August 1975 & I 84 & $20 \% 4$ & $17 \cdot 1$ & $\mathrm{I} \cdot 5$ & $4 \cdot I$ & 5 & 9 & -90 & 385 \\
\hline 9. September-October I 975 & I93 & 144 & $18 \cdot 5$ & $4 \cdot 2$ & $6 \cdot 9$ & 7 & II & 59 & 493 \\
\hline May 1974-October 1975 & 1210 & $13 \cdot 7$ & $I 7 \cdot I$ & $I \cdot 4$ & $4: 3$ & 7 & 9 & 88 & $4 \mathrm{I} 6$ \\
\hline
\end{tabular}

* Duration of illness (d) in the interval between adjacent routine clinic visits $\div$ total duration (d) of interval between visits $\times 100$, where the interval varied from 3 to 10 weeks, and was standardized to I calendar month.

$\dagger$ The mean ages for each group varied from $I \cdot 4$ to $I \cdot 8$ years, over-all mean $I \cdot 60$ years.

\section{Seasonal variation in growth in relation to infection}

The Gambia has two markedly different seasons in the year, a dry season extending from mid-November to mid-June, and the remaining 5 months which constitute a rainy season. The dramatic difference in growth patterns during these two seasons has been comprehensively documented by McGregor et al. (1968). To determine the influence of seasonal changes the values were analysed for nine periods of 2 months. The results, given in Table 2, clearly show the seasonal nature of growth retardation and infection in Keneba. Gastroenteritis was more common from May to October, peaking during July and August in both 1974 and 1975, while during the remaining months the prevalence was considerably less. The notable exception was a sudden epidemic producing a peak in January-February, 1975, which was quite unrepresentative of the normal course of events (I. A. McGregor, personal communication).

During July-August, 1975, the prevalence of gastroenteritis peaked at $20.4 \%$, which suggests that the average child had gastroenteritis for $20.4 \%$ of this period. Predictably malaria, which is usually an acute illness of short duration, had lower prevalence values (maximum $4.2 \%$ ) and showed stronger seasonal variation. Although the effect on growth of a given prevalence of malaria was greater than for the same prevalence of gastroenteritis (Table I) its total effect on growth was far less due to this lower mean prevalence. Table 2 shows that malaria occurred more often in I 975 and only in this year was its effect on growth significant.

Table 2 also shows the marked seasonal variations in growth rate. Growth faltering was evident during much of the year. Mean growth rates for a reference population (Jelliffe, 1966) at 6 months of age were $17 \mathrm{~mm} /$ month and $570 \mathrm{~g} /$ month. At $3^{6}$ months 


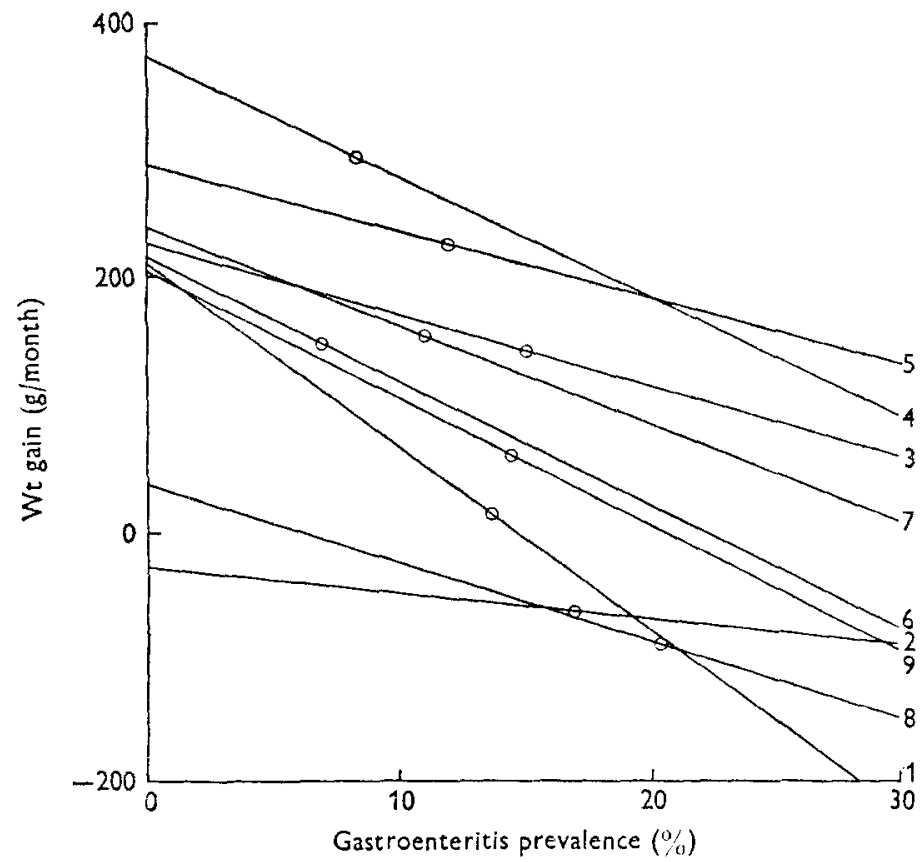

Fig. 2. Fitted regression lines of weight gain of Gambian village children $v$. gastroenteritis prevalence (duration of illness (d) in the interval between adjacent routine clinic visits $\div$ total duration (d) of interval between visits $\times 100$, where the interval varied from 3 to 10 weeks and was standardized to $I$ calendar month) for nine periods of 2 months (for details, see Table 2) from May 1974 to October 1975, during a study of nutritional status.

the corresponding values were $6.5 \mathrm{~mm} /$ month and $160 \mathrm{~g} /$ month. Mean values over this age range were $10 \mathrm{~mm} / \mathrm{month}$ and $240 \mathrm{~g} /$ month. Values for height gain and weight gain of children from Keneba were much lower than these mean values for July-October and showed little evidence of 'catch-up' during the rest of the year.

Fig. 2 gives the fitted regression lines for weight gain $v$. gastroenteritis prevalence for the nine seasonal groups. The point where each regression line intersects the growth axis, the intercept, represents the mean growth that could have been expected in that period had there been no gastroenteritis. During July-August, both in 1974 and 1975, effectively no growth would have occurred even in the absence of gastroenteritis. Conversely, between November 1974 and February 1975 some extent of 'catch-up' growth could have been expected, 290-375 g/month. For the remainder of the period studied the rate of growth would have approached the standard value of $240 \mathrm{~g} /$ month, but there would have been no opportunity for 'catch-up'. Assuming parallelism of the slopes these differences in the intercepts are very highly significant $(P<0.001)$.

The analysis so far has assumed that the effect of a given level of gastroenteritis was to reduce the growth rate by an absolute amount, independent of the age and weight of the child. A given amount of weight faltering could be more important in a child weighing $5 \mathrm{~kg}$ than in one weighing $10 \mathrm{~kg}$, since it represents a larger proportion of the child's weight. An analysis of log weight gain effectively expresses 
gain in weight as a proportion of the mean weight of the child for a given interval. On this basis the regression coefficient for gastroenteritis is $-95 \pm 8 \cdot 5 \mathrm{~g} / \mathrm{kg}$ bodyweight per month. This value was still highly significant $(t \mathrm{II} \cdot 2, P<0.00 \mathrm{r})$.

It was also possible that the effect of gastroenteritis varied with the age of the child. This possibility was investigated using an 'age $\times$ gastroenteritis' term in the regression calculation, allowing the regression coefficient of weight gain $v$. gastroenteritis to change linearly with age. However, the interactions were non-significant for both weight gain and $\log$ weight gain $(P>0 \cdot 1)$.

\section{DISCUSSION}

The most widely used methods for assessing nutritional status are those based on anthropometry. Seone \& Latham (197I) and Waterlow (1972, 1973) proposed that reduced height-for-age (retardation or stunting) reflects previous long-term dietary deprivation while weight-for-height reflects current nutritional status.

Nutritionists often assume that growth deficit is predominantly the product of dietary inadequacy. Our results and those of Martorell et al. (I975) however, have shown quantitatively how both growth in weight and even in height were significantly affected by infection, gastroenteritis and malaria in the present study. This finding is important for various reasons. Any attempt at assessing nutritional status which is based entirely on anthropometric measurements can give no indication of the relative importance of dietary and other factors in the aetiology of the syndrome. These are measurements of growth failure and wasting and may reflect only imprecisely the extent of dietary deficiency in a community. Neither should anthropometry be used as the only criterion of the effectiveness of a dietary supplementation programme. Except in an emergency famine situation there is no real alternative but to support anthropometric measurements with an investigation of dietary intake patterns and to assess the quantitative role of disease and other health factors in the growthfaltering process.

It has already been shown by others that severe clinically recognizable forms of protein-energy malnutrition may follow gastroenteritis (McKenzie, Lovell, Standard \& Miall, 1967; Morley, Bicknell \& Woodland, 1968). The concept of weanling diarrhoea has often been stressed in a context of weaning habits and environmental hygiene (Jelliffe, I968). Poskitt (I972) has drawn attention to the importance of seasonal infective diarrhoea.

More recently, Martorell et al. (I975) have quantified the relationship between diarrhoea and growth in rural Guatemalan children, finding that in children up to 7 years old, those in a high-prevalence diarrhoea group grew appreciably less in length and weight than those in a low-prevalence diarrhoea group. This relationship was not found for growth and fever or respiratory illnesses. They found diarrhoea more strongly related to gain in length than gain in weight, in contrast to the findings of the present study. However, their estimates of growth were based on measurements made 6 months or I year apart; although this would give more accurate estimates of growth over the interval, it would be at a cost of reduced sensitivity to short-term changes. However, height is not a labile measurement, so that increasing the interval 
between measurements will improve its relationship with infection. Weight, on the other hand, is extremely labile, and over an interval of 6 months will have time to be affected by disease and make up the deficit. For this reason their study could not be expected to incriminate diseases which have a relatively short and sharp effect on growth, for example malaria.

The analysis in the present study pooled the results for different children, so the possibility exists that some of the children perpetually had diarrhoea, and perpetually grew slowly, while others grew well and had little diarrhoea. This situation would have led to the observed findings, but would have been due to differences 'between children', not to differences 'within children'. To guard against this, the analysis was repeated with the differences between individuals removed, so that each individual became his own control. The relationship between diarrhoea and growth was in fact slightly more significant by this type of analysis compared with that given in Table I, emphasizing that the observed findings are valid within individuals: a child will grow less well when he has diarrhoea than when he has not.

Our study and that of Martorell et al. (1975) have both demonstrated the very strong relationship between gastroenteritis and growth faltering irrespective of aetiology and the metabolic mechanisms involved. It must not be forgotten that gastroenteritis defined here as a diarrhoeal illness may have many causes and there could be different mechanisms whereby nutritional status as measured by anthropometry can be affected. If a child is vomiting, his dietary intake of nutrients is bound to be curtailed. Furthermore, there will be an additional loss of nutrients from the gut because of the diarrhoea. High plasma cortisol concentrations, increased in response to the infection, will inhibit the utilization of amino acids for growth (Lunn, Whitehead, Baker \& Austin 1976).

The quantitative importance of gastroenteritis in Keneba can be illustrated by the fact that except during the 2 months of July and August, normal rates of growth for children in the second and third years of life, and even slight 'catch-up', could have been expected had it not been for the gastroenteritis. The role of diet in a programme directed at improving the nutritional status of this community needs to be critically evaluated.

Although malaria was shown to be highly significantly related to weight faltering, it was quantitatively less important than gastroenteritis because it was absent for more than half the year. However, this may underestimate the potential effect of malaria on growth for two reasons: (a) subjects presenting with malaria were usually treated actively, thus modifying the natural history of the disease, and $(b)$ the lack of a relationship between malaria and growth during the first rainy season may have been due to an exceptionally low prevalence of malaria in 1974, at the end of the Sahelian drought (I. A. McGregor, personal communication; A. M. Thomson, personal communication).

It may seem surprising that measles, already shown by other workers to have a profound effect on nutritional status (Morley, 1962; Murphey, 1966; Poskitt, 1971), has not been highlighted in this study. This was because only two cases of measles occurred and a subsequent probable epidemic was averted by vaccination of remaining 
susceptibles. In the circumstances there was no alternative but to knowingly alter the natural pattern of events in the village.

Equally one may speculate on the extent to which a resident medical officer (M.G.M.R.) modified the pattern of other infectious diseases. Bearing in mind, however, that the extent of weight faltering was such that by the age of 18 months the average child was only $75 \%$ of the expected weight-for-age and more than two-thirds of the children underweight by current international nutritional standards (Jelliffe, I 966), the conclusion must be drawn that a conventional 'therapeutic' medical service has failed to deal effectively with the infection-induced element in the weight faltering occurring in Keneba.

The authors wish to acknowledge that the measurements of height and weight were largely carried out by Dr and Mrs J. B. Mason. We are grateful to Mr Lamin Bojang who carried out the examination of blood films for malaria and stools for parasites. We also received valuable technical advice from Mr C. Pyne, Mr K. Crane and Dr W. G. Harris. Sister M. A. Hood and Dr S. G. J. Goh (Mrs Rowland) helped in providing a medical service. The nursing and medical staff at the Medical Research Council Ward in Fajara provided inpatient care for those children requiring hospitalization. Mr K. C. Day assisted with the computer analysis and Dr I. A. McGregor and Professor A. M. Thomson provided valuable discussion and advice both on the design of the project and on the interpretation of the results. Dr R.S. Bray made available the accommodation in Keneba which made the investigation possible.

\section{REFERENCES}

Court, S. D. M. (1963). Medical Care of Children. Oxford and London: Oxford University Press.

Frood, J. D. L., Whitehead, R. G. \& Coward, W. A. (I97I). Lancet ii, ro47.

Jelliffe, D. B. (1966). Wld Hlth Org. Monogr. Ser. No. 53.

Jelliffe, D. B. (1968). Infant Nutrition in the Subtropics and Tropics, and ed., p. 53. Geneva: World Health Organization.

Lunn, P. G., Whitehead, R. G., Baker, B. A. \& Austin, S. (1976). Br. F. Nutr. 36, 537.

McGregor, I. A., Rahman, A. K., Thompson, B., Billewicz, W. Z. \& Thomson, A. M. (1968). Trans. R. Soc. trop. Med. Hyg. 62, 34I.

McGregor, I. A., Rahman, A. K., Thomson, A. M., Billewicz, W. Z. \& Thompson, B. (I970). Trans. R. Soc. trop. Med. Hyg. 64, 48 .

McKenzie, H. I., Lovell, H. G., Standard, K. L. \& Miall, W. E. (1967). Millbank Memorial Fund Quarterly 45, 303.

Martorell, R., Habicht, J. P., Yarbrough, C., Lechtig, A., Klein, R. E. \& Western, K. A. (1975). Am. F. dis. Childh. r29, 1296.

Mata, L. J., Jimenez, F., Cordon, M., Rosales, R., Prera, E., Schneider, R. E. \& Viteri, F. E. (1972). Am. J. clin. Nutr. 25, x 18.

Mata, L. J., Urrutia, J. J. \& Gordon, J. E. (1967). Trop. geogr. Med. 19, 247.

Morley, D. C. (1962). Am. F. dis. Childh. 103, 230.

Morley, D. C., Bicknell, J. \& Woodland, M. (1968). Trans. R. Soc. trop. Med. Hyg. 62, 164.

Murphey, E. L. (rg66). Ghana med. F. 5, 58 .

Poskitt, E. M. E. (1971). Lancet ii, 517.

Poskitt, E. M. E. (1972). Trans. R. Soc. trop. Med. Hyg. 66, 931.

Scrimshaw, N. S. (r975). In Protein-Calorie Malnutrition, [R. E. Olson, editor]. New York and London: Academic Press.

Scrimshaw, N. S., Taylor, C. E. \& Gordon, J. E. (1968). Wld Hlth Org. Monogr. Ser. No. 57.

Seone, N. \& Latham, M. C. (1971). F. trop. Pediat. Env. Child Hlth 17, 98.

Waterlow, J. C. (1972). Br. med. $\mathcal{F}$. iii, 566.

Waterlow, J. C. (1973). Lancet ii, 87. 